Вісник Харківського національного університету імені В.Н. Каразіна Серія "Математика, прикладна математика і механіка" Том 90, 2019, с. 4-25

УДК 517.9
Visnyk of V.N.Karazin Kharkiv National University Ser. "Mathematics, Applied Mathematics and Mechanics"

Vol. 90, 2019, p. 4-25

DOI: $10.26565 / 2221-5646-2019-90-01$

\title{
Discrete mathematical model of the scattering process of E-polarized wave on a periodic impedance grating
}

\author{
V.D. Dushkin ${ }^{1}$, S.V. Zhuchenko², O.V. Kostenko ${ }^{3}$ \\ ${ }^{1}$ National Academy of the National Guard of Ukraine, \\ Zakhystnykiv Ukrainy Sq. 3, Kharkiv, 61001, Ukraine \\ ${ }^{2}$ V. N. Karazin Kharkiv National University, \\ Svobody Sq. 4, Kharkiv, 61022, Ukraine \\ ${ }^{3}$ B. Verkin Institute for Low Temperature Physics and Engineering, \\ Nauky Ave., 47, Kharkiv, 61103, Ukraine \\ dushkinvd@gmail.com,stanislavzhuchenko@ukr.net, alexvladkost@gmail.com
}

It is considered the discrete mathematical models which describe the interaction process of the E-polarized wave and periodic system of impedance tapes. It is shown that the discrete model for various values of the discretization parameter is equivalent to the system of singular integral equations. Calculations were performed for the proposed model and for the model based on the hypersingular equations. The obtaining results showed the closeness of the field characteristics.

Keywords: mathematical model; impedance structures; numerical experiment.

Душкін В.Д, Жученко С.В., Костенко О.В. Дискретна математична модель процесу розсіювання хвиль періодичною імпедансною граткою. У роботі розглянуто дискретні математичні моделі, які описують процес взаємодії Е-поляризованої хвилі з періодичною системою імпедансних стрічок. Дискретна модель при різних значеннях параметра дискретизації еквівалентна відповідній системі сингулярних інтегральних рівнянь. Обчислення проводилися на базі запропонованої моделі та на основі моделі, що спирається на гіперсінгулярні рівняння.

Ключові слова: математична модель; імпедансні структури; чисельний експеримент.

Душкин В.Д., Жученко С.В., Костенко А.В. Дискретная математическая модель процесса рассеяния волн периодической импедансной решёткой. В работе рассмотрены дискретные математические модели, описывающие процесс взаимодействия Е-поляризованной волны с периодической системой импедансных лент. Показано, что дискретная модель при различных значениях параметра дискретизации эквивалентна соответствующим системам сингулярных интегральных уравнений. Вычисления проводились на основе предлагаемой модели и модели, основанной на гиперсингулярных уравнениях. Полученные результаты оказались близки. Ключевые слова: математическая модель; импедансные структуры; численный эксперимент.

2010 Mathematics Subject Classification: 41A55.

(C) V.D. Dushkin, S. V.Zhuchenko, O. V. Kostenko, 2019 


\section{Origins of research.}

Shchukin-Leontovich impedance boundary conditions are widely used to describe the interaction processes of electromagnetic waves and different kind of non-PEC structures [1] - [8]. In this case, the 3D-problem for Maxwell's equations reduces to two $2 \mathrm{D}$-problems. They are boundary value problems for the Helmholtz equation with third boundary conditions. In order to find an approximate solution to these problems, we use the two-stage algorithm of professor Yu. V. Gandel. At the first step, we find systems of integral equations that are equivalent to the original boundary value problem. We are using the method of parametric representations of integral operators [9] - [11] on this step. At the second step, a discrete mathematical model of the mentioned problem is built. The discrete singularities method [12], [13] was used to obtain it. This approach has shown its effectiveness in solving various problems[14] - [36]. In [13], [36], the method of reducing the initial boundary-value problem to a system consisting of singular equations of the first kind and Fredholm integral equations of the second kind is considered. We propose a discrete mathematical model of the problem under study based on the system of integral equations mentioned above. It is shown that a one-to-one correspondence exists between discrete models for various values of the discretization parameter and systems of approximating integral equations of the problem. By solving this system, the approximate values of the main field characteristics are determined. The method of parametric representations of integral operators makes it possible to obtain systems of integral equations of other types [29], [30]. In particular, the original boundary-value problem was reduced to a system consisting of hypersingular integral equations of the second kind and the Fredholm integral equation of the second kind [32], [37]. Therefore, it is a good base of interest for a comparative computer experiment.

\section{Formulation of the problem}

$$
\begin{aligned}
& \text { Let } T=\bigcup_{n=-\infty}^{\infty} \bigcup_{q=1}^{M} T_{n, q} \text { be a system of non-PEC tapes } \\
& T_{n, q}=\left\{\left(x^{\prime}, y^{\prime}, z^{\prime}\right) \in R^{3} \mid x^{\prime} \in R, y^{\prime}=\left(\alpha_{q}^{\prime}+2 n l^{\prime}, \beta_{q}^{\prime}+2 n l^{\prime}\right), z^{\prime}=0\right\} .
\end{aligned}
$$

E-polarized wave

$$
\begin{gathered}
\vec{E}^{(\text {initial })}=\left(E_{0}, 0,0\right), \quad \vec{H}^{(\text {initial })}=\left(0, \frac{1}{i \omega \mu \mu_{0}} \cdot \frac{\partial E_{0}}{\partial z^{\prime}},-\frac{1}{i \omega \mu \mu_{0}} \cdot \frac{\partial E_{0}}{\partial y^{\prime}}\right), \\
E_{0}\left(y^{\prime}, z^{\prime}\right)=\exp \left(i k\left(y^{\prime} \cdot \sin \varphi-z^{\prime} \cdot \cos \varphi\right)\right) \cdot \exp (-i \omega t)
\end{gathered}
$$

is scattered by this tape system. We consider the problem as formulated in [13] and [36]. This problem amounts to finding a function $E\left(y^{\prime}, z^{\prime}\right)$ that corresponds to the $\mathrm{x}$-component of the total field, resulting from waves scattering by tapes. 


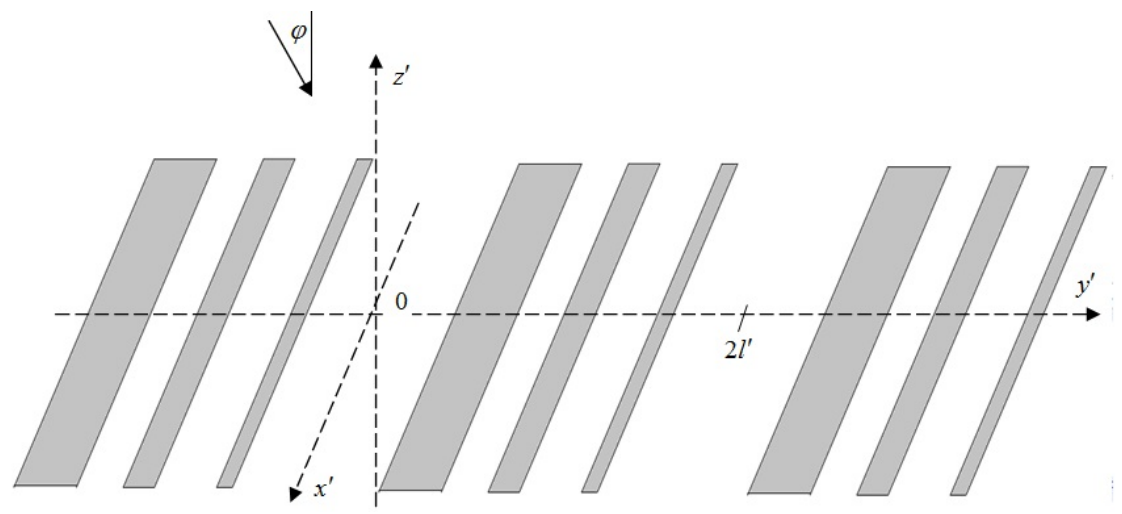

Fig.1 Impedance structure.

It is the solution of the Helmholtz equation:

$$
\triangle E+k^{2} \cdot E=0, k=\frac{\omega}{c},
$$

in the whole plane without tapes. The total field satisfies

1) Shchukin - Leontovich boundary conditions on tapes:

$$
\frac{\partial E}{\partial n^{\prime}}-h^{\prime} \cdot E=0, \quad\left(y^{\prime}, z^{\prime}\right) \in T,
$$

2) Floquet conditions,

3) Boundedness energy condition in any region of the plane.

Also the difference between total and incident field $E-E_{0}$ satisfies the Sommerfeld radiation conditions.

\section{Systems of integral equations.}

Put

$$
E\left(y^{\prime}, z^{\prime}\right)-E_{0}\left(y^{\prime}, z^{\prime}\right)= \begin{cases}E^{+}\left(y^{\prime}, z^{\prime}\right), & z^{\prime}>0 \\ E^{-}\left(y^{\prime}, z^{\prime}\right), & z^{\prime}<0\end{cases}
$$

where

$$
\begin{aligned}
E^{+}\left(y^{\prime}, z^{\prime}\right) & =\sum_{n=-\infty}^{\infty} a_{n}^{+} \cdot \exp \left(-\gamma_{n}^{\prime} z^{\prime}\right) \cdot \exp \left(i p_{n}^{\prime} y^{\prime}\right), \\
E^{-}\left(y^{\prime}, z^{\prime}\right) & =\sum_{n=-\infty}^{\infty} a_{n}^{-} \cdot \exp \left(\gamma_{n}^{\prime} z^{\prime}\right) \cdot \exp \left(i p_{n}^{\prime} y^{\prime}\right)
\end{aligned}
$$

and

$$
\begin{gathered}
p_{n}^{\prime}=k \cdot \sin \varphi+\frac{\pi n}{l^{\prime}}, \gamma_{n}^{\prime}=\sqrt{\left(p_{n}^{\prime}\right)^{2}-k^{2}}, n \in Z ; \\
\operatorname{Re}\left(\gamma_{n}^{\prime}\right) \geq 0, \operatorname{Im}\left(\gamma_{n}^{\prime}\right) \leq 0, n \in Z .
\end{gathered}
$$


Hereinafter we use the notation:

$$
\begin{gathered}
\kappa=\frac{l^{\prime} \cdot k}{\pi}, y=\frac{\pi}{l^{\prime}} \cdot y^{\prime}, z=\frac{\pi}{l^{\prime}} \cdot z^{\prime}, h=\frac{l^{\prime} \cdot h^{\prime}}{\pi} ; \\
p_{n}=\frac{l^{\prime} \cdot p_{n}^{\prime}}{\pi}=\kappa \cdot \sin \varphi+n, \quad \gamma_{n}=\frac{l^{\prime} \cdot \gamma_{n}^{\prime}}{\pi}, n \in N ; \\
\alpha_{q}=\frac{\pi}{l^{\prime}} \cdot \alpha_{q}^{\prime}, \quad \beta_{q}=\frac{\pi}{l^{\prime}} \cdot \beta_{n}^{\prime}, q=1, \ldots, M ; \\
L=\bigcup_{q=1}^{M} L_{q}, \quad L_{q}=\left(\alpha_{q}, \beta_{q}\right) .
\end{gathered}
$$

From field continuity condition

$$
\begin{gathered}
E^{+}(y, 0)=E^{-}(y, 0), y \in C L=[0,2 \pi] \backslash L ; \\
\frac{\partial E^{+}}{\partial z}(y, 0)=\frac{\partial E^{-}}{\partial z}(y, 0), y \in C L
\end{gathered}
$$

and the boundary conditions (5) we get:

$$
\begin{gathered}
\sum_{n=-\infty}^{\infty} \gamma_{n} \cdot\left(a_{n}^{+}+a_{n}^{-}\right) \cdot \exp \left(i p_{n} y\right)=0, y \in C L \\
\sum_{n=-\infty}^{\infty}\left(\gamma_{n}+h\right) \cdot\left(a_{n}^{+}+a_{n}^{-}\right) \cdot \exp \left(i p_{n} y\right)=-2 h \cdot \exp (i \kappa y \sin \varphi), y \in L ; \\
\sum_{n=-\infty}^{\infty}\left(a_{n}^{+}-a_{n}^{-}\right) \cdot \exp \left(i p_{n} y\right)=0, y \in C L ; \\
\sum_{n=-\infty}^{\infty}\left(\gamma_{n}+h\right) \cdot\left(a_{n}^{+}-a_{n}^{-}\right) \cdot \exp \left(i p_{n} y\right)=-2 i \kappa \cos \varphi \cdot \exp (i \kappa y \sin \varphi), y \in L .
\end{gathered}
$$

Acting as in the monograph [13], we define two functions:

$$
\begin{array}{r}
W^{+}(y)=\frac{\partial u^{-}}{\partial z}(y, 0)-\frac{\partial u^{+}}{\partial z}(y, 0)=\sum_{n=-\infty}^{\infty} \gamma_{n}\left(a_{n}^{+}+a_{n}^{-}\right) \exp \left(i p_{n} y\right), \\
y \in[0,2 \pi] . \\
W^{-}(y)=\frac{\partial u^{+}}{\partial y}(y, 0)-\frac{\partial u^{-}}{\partial y}(y, 0)=\sum_{n=-\infty}^{\infty} i p_{n}\left(a_{n}^{+}-a_{n}^{-}\right) \exp \left(i p_{n} y\right), \\
y \in[0,2 \pi] .
\end{array}
$$

It implies from (14), (15), that: 


$$
\begin{gathered}
W^{+}(y)=0, W^{-}(y)=0, y \in C L ; \\
\int_{L_{q}} W^{-}(t) d t=0,(q=1, \ldots, M) ; \\
E^{+}(y, 0)-E^{-}(y, 0)=\sum_{n=-\infty}^{\infty}\left(a_{n}^{+}-a_{n}^{-}\right) \exp \left(i p_{n} y\right)=\int_{\alpha_{q}}^{y} W^{-}(t) d t .
\end{gathered}
$$

Using the inverse Fourier transform and taking into account $(22)-(23)$ we obtain:

$$
\begin{gathered}
a_{n}^{+}=\frac{1}{4 \pi \gamma_{n}} \int_{L} W^{+}(t) \cdot \exp \left(-i p_{n} t\right) d t+ \\
+\frac{1}{4 \pi i p_{n}} \int_{L} W^{-}(t) \cdot \exp \left(-i p_{n} t\right) d t, n \in Z ; \\
a_{n}^{-}=\frac{1}{4 \pi \gamma_{n}} \int_{L} W^{+}(t) \cdot \exp \left(-i p_{n} t\right) d t- \\
-\frac{1}{4 \pi i p_{n}} \int_{L} W^{-}(t) \cdot \exp \left(-i p_{n} t\right) d t, n \in Z .
\end{gathered}
$$

As proposed in [13], we accomplished the conversions to (17) and get the second-kind Fredholm integral equation:

$$
\begin{array}{r}
W^{+}(y)-\frac{h}{\pi} \int_{L} \ln \left|2 \cdot \sin \frac{y-t}{2}\right| W^{+}(t) d t+ \\
+\frac{h}{\pi} \int_{L} Q(y, t) W^{+}(t) d t=-2 h \cdot \exp (i \kappa y \sin \varphi), y \in L ;
\end{array}
$$

where

$$
\begin{gathered}
Q(y, t)=\exp (i \kappa \sin \varphi(y-t)) \cdot\left(\frac{1}{2 \gamma_{0}}+\sum_{\substack{n=-\infty \\
n \neq 0}}^{\infty} \frac{\triangle_{n}^{+}}{2} \exp (i n(y-t))\right)- \\
-(\exp (i \kappa \sin \varphi(y-t))-1) \cdot \ln \left|2 \cdot \sin \frac{y-t}{2}\right| ; \\
\triangle_{n}^{+}=\frac{1}{\gamma_{n}}-\frac{1}{|n|}=O\left(\frac{1}{n^{2}}\right), n \rightarrow \infty .
\end{gathered}
$$


This equation contains a logarithmic singularity in the kernel. Having applied the method of parametric representations of integral transformations, we obtain a singular integral equation:

$$
\begin{aligned}
& -\frac{1}{2 \pi} \int_{L} \operatorname{ctg}\left(\frac{t-y}{2}\right) W^{-}(t) d t+\frac{1}{\pi} \int_{L} R(y, t) W^{-}(t) d t+ \\
& +h \cdot \int_{\alpha_{1}}^{y} W^{-}(t) d t=-2 i \kappa \cos \varphi \cdot \exp (i \kappa y \sin \varphi), y \in L,
\end{aligned}
$$

with additional conditions:

$$
\int_{\alpha_{q}}^{\beta_{q}} W^{-}(t) d t=0,(q=1, \ldots, M),
$$

where

$$
\begin{gathered}
R(y, t)=\sum_{\substack{n=-\infty \\
n \neq 0}}^{\infty} \frac{\triangle_{n}^{-}}{2 i p_{n}} \exp \left(i p_{n}(y-t)\right)+ \\
+\frac{\kappa \cos \varphi}{2} \cdot \sum_{\substack{n=-\infty \\
n \neq 0}}^{\infty}\left(\frac{1}{p_{n}}-\frac{1}{n}\right) \exp \left(-i p_{n} t\right)- \\
\quad-i \kappa \cos \varphi \cdot \frac{\pi-t}{2} \cdot \exp (-i \kappa \sin \varphi \cdot t)- \\
-\frac{\exp (i \kappa \sin \varphi(y-t))-1}{2} \cdot \operatorname{ctg}\left(\frac{t-y}{2}\right) ; \\
\triangle_{n}^{-}=\gamma_{n}-|n|-\kappa \sin \varphi \cdot \frac{|n|}{n}=O\left(\frac{1}{n}\right), n \rightarrow \infty .
\end{gathered}
$$

Making the substitution of y by 0 in (18) and taking into account (25) - (26), we obtain

$$
\begin{gathered}
a_{0}^{+}-a_{0}^{-}=-\sum_{\substack{n=-\infty \\
n \neq 0}}^{\infty}\left(a_{n}^{+}-a_{n}^{-}\right)= \\
=-\frac{1}{\pi} \int_{L} \exp (-i \kappa \sin \varphi \cdot t) \cdot \sum_{\substack{n=-\infty \\
n \neq 0}}^{\infty} \frac{1}{2 i}\left(\frac{1}{p_{n}}-\frac{1}{n}\right) \exp (-i n t) \cdot W^{-}(t) d t+ \\
+\frac{1}{\pi} \int_{L} \frac{\pi-t}{2} \cdot e^{-i \kappa \sin \varphi \cdot t} \cdot W^{-}(t) d t .
\end{gathered}
$$


Define the functions:

$$
\begin{aligned}
& V_{q}^{+}(y)=W^{+}(y) \sqrt{\left(y-\alpha_{q}\right)\left(\beta_{q}-y\right)}, y \in L_{q},(1 \ldots, M) ; \\
& V_{q}^{-}(y)=W^{-}(y) \sqrt{\left(y-\alpha_{q}\right)\left(\beta_{q}-y\right)}, y \in L_{q},(1 \ldots, M) ;
\end{aligned}
$$

It implies from the boundedness energy condition that $V_{q}^{+}(y) \in C\left[\alpha_{q}, \beta_{q}\right]$ and $V_{q}^{-}(y) \in C\left[\alpha_{q}, \beta_{q}\right],(q=1, \ldots, M)$.

Define mappings:

$$
\begin{array}{r}
g_{q}:[-1,1] \rightarrow\left[\alpha_{q}, \beta_{q}\right], g_{q}(t)=\phi_{q} \cdot t+\frac{\beta_{q}+\alpha_{q}}{2}, \\
\phi_{q}=\frac{\beta_{q}-\alpha_{q}}{2}, \quad(q=1, \ldots, M),
\end{array}
$$

and notation:

$$
\begin{array}{r}
K_{q, p}^{+}(\xi, \tau)=\phi_{q} \cdot h\left\{Q\left(g_{q}(\xi), g_{p}(\tau)\right)-\ln \left|2 \cdot \sin \frac{g_{p}(\tau)-g_{q}(\xi)}{2}\right|\right. \\
\left.+\delta_{q p} \cdot \ln |\tau-\xi|\right\},(q=1, \ldots, M),(p=1, \ldots, M) ; \\
K_{q, p}^{-}(\xi, \tau)=\phi_{q} \cdot\left\{\frac{1}{2} \operatorname{ctg}\left(\frac{g_{p}(\tau)-g_{q}(\xi)}{2}\right)-R\left(g_{q}(\xi), g_{p}(\tau)\right)\right\}-\frac{\delta_{q p}}{\tau-\xi}, \\
(q=1, \ldots, M),(p=1, \ldots, M) . \\
f_{1, q}(\xi)=-2 \phi_{q} \cdot h \cdot \sqrt{1-\xi^{2}} \cdot \exp \left(i \kappa g_{q}(\xi) \sin \varphi\right),(q=1, \ldots, M), \\
f_{2, q}(\xi)=2 i \kappa \phi_{q} \cdot \cos \varphi \cdot \exp \left(i \kappa g_{q}(\xi) \sin \varphi\right),(q=1, \ldots, M) .
\end{array}
$$

In (38)-(39) symbol $\delta_{q p}$ is the Kronecker delta. Taking into account (35), (38) from equation (27) we obtain:

$$
\begin{array}{r}
V_{q}^{+}(\xi)-\frac{h \phi_{q}}{\pi} \cdot \sqrt{1-\xi^{2}} \int_{-1}^{1} \ln |\tau-\xi| \frac{V_{q}^{+}(\tau) d \tau}{\sqrt{1-\tau^{2}}}+ \\
+\frac{1}{\pi} \sum_{p=1}^{M} \int_{-1}^{1} K_{q, p}^{+}(\xi, \tau) \frac{V_{p}^{+}(\tau) d \tau}{\sqrt{1-\tau^{2}}}=f_{1, q}(\xi), \\
|\xi|<1,(q=1, \ldots, M) .
\end{array}
$$


The system of singular integral equations:

$$
\begin{array}{r}
\frac{1}{\pi} \int_{-1}^{1} \frac{1}{\tau-\xi} \frac{V_{q}^{-}(\tau) d \tau}{\sqrt{1-\tau^{2}}}+\frac{1}{\pi} \sum_{p=1}^{M} \int_{-1}^{1} K_{q, p}^{-}(\xi, \tau) \frac{V_{p}^{-}(\tau) d \tau}{\sqrt{1-\tau^{2}}}- \\
-h \phi_{q} \cdot \int_{-1}^{\xi} \frac{V_{p}^{-}(\tau) d \tau}{\sqrt{1-\tau^{2}}}=f_{2, q}(\xi), \\
|\xi|<1,(q=1, \ldots, M)
\end{array}
$$

with additional conditions:

$$
\int_{-1}^{1} \frac{V_{q}^{-}(\tau) d \tau}{\sqrt{1-\tau^{2}}}=0,(q=1, \ldots, M)
$$

is a consequence of the equations (30), (31) and notations (36), (39).

\section{The mathematical model of the problem}

We denote by $\left\{t_{1, n, k}\right\}_{k=1}^{n}$ the Chebyshev nodes, which are zeros of Chebychev polynomials $T_{n}(\tau)$ of degree $n$. Also we consider the collocation points $\left\{t_{2, n, m}\right\}_{m=1}^{n-1}$, which are the zeros of Chebychev polynomials of the second kind $U_{n-1}(\tau)$.

As in [38] - [40] we took into consideration the basis (fundamental) polynomials:

$$
\begin{gathered}
l_{1, n-1, k}(\tau)=\frac{P_{n}(\tau)}{P_{n}^{\prime}\left(t_{1, n, k}\right)\left(\tau-t_{1, n, k}\right)}, \quad k=1, \ldots, n ; \\
l_{2, n-2, m}(\xi)=\frac{U_{n-1}(\xi)}{U_{n-1}^{\prime}\left(t_{2, n, m}\right)\left(\xi-t_{2, n, m}\right)}, \quad m=1, \ldots, n-1 .
\end{gathered}
$$

We introduce the Lagrange interpolation polynomials of functions and

$$
\begin{array}{r}
K_{q, p, n}^{+}(\xi, \tau)=\sum_{m=1}^{n} \sum_{k=1}^{n} K_{q, p}^{+}\left(t_{1, n, m}, t_{1, n, k}\right) \cdot l_{1, n, m}(\xi) \cdot l_{1, n, k}(\tau), \\
q=1, \cdots, M ; \quad p=1, \cdots, M ; \\
K_{q, p, n}^{-}(\xi, \tau)=\sum_{m=1}^{n} \sum_{k=1}^{n} K_{q, p}^{-}\left(t_{2, n, m}, t_{1, n, k}\right) \cdot l_{2, n, m}(\xi) \cdot l_{1, n, k}(\tau), \\
q=1, \cdots, M ; \quad p=1, \cdots, M ;
\end{array}
$$




$$
\begin{array}{r}
f_{1, q, n}(\xi)=\sum_{m=1}^{n} f_{1, q}\left(t_{1, n, m}\right) \cdot l_{1, n, m}(\xi), \\
f_{2, q, n}(\xi)=\sum_{m=1}^{n} f_{2, q}\left(t_{2, n, m}\right) \cdot l_{2, n, m}(\xi), \\
q=1, \cdots, M .
\end{array}
$$

Let us consider the following system of integral equations:

$$
\begin{aligned}
& V_{q, n}^{+}(\xi)-\frac{\phi_{q} \cdot h}{\pi} \cdot \sum_{m=1}^{n} \sqrt{1-\left(t_{2, n, m}\right)^{2}} \cdot l_{2, n, m}(\xi) \int_{-1}^{1} \ln \left|\tau-t_{2, n, m}\right| \frac{V_{q, n}^{+}(\tau) d \tau}{\sqrt{1-\tau^{2}}} \\
& +\frac{1}{\pi} \sum_{p=1}^{M} \int_{-1}^{1} K_{q, p, n}^{+}(\xi, \tau) \frac{V_{p, n}^{+}(\tau) d \tau}{\sqrt{1-\tau^{2}}}=f_{1, q, n}(\xi) \\
& |\xi|<1, \quad q=1, \cdots, M ; \\
& \frac{1}{\pi} \int_{-1}^{1} \frac{1}{\tau-\xi} \cdot \frac{V_{q, n}^{-}(\tau) d \tau}{\sqrt{1-\tau^{2}}}+\frac{1}{\pi} \sum_{p=1}^{M} \int_{-1}^{1} K_{q, p, n}^{-}(\xi, \tau) \frac{V_{p, n}^{-}(\tau) d \tau}{\sqrt{1-\tau^{2}}}- \\
& -\phi_{q} \cdot h \int_{-1}^{\xi} \frac{V_{q, n}^{-}(\tau) d \tau}{\sqrt{1-\tau^{2}}}=f_{2, q, n}(\xi) \\
& |\xi|<1, \quad q=1, \cdots, M ; \\
& \int_{-1}^{1} \frac{V_{q, n}^{-}(\tau) d \tau}{\sqrt{1-\tau^{2}}}=0, \quad q=1, \cdots, M
\end{aligned}
$$

Designate as $L_{\rho,-1}^{2}$ the Hilbert spaces of measurable on segment $[-1,1]$ functions with the inner product

$$
(U, V)=\int_{-1}^{1} U(\tau) \cdot \bar{V}(\tau) \cdot \frac{d \tau}{\sqrt{1-\tau^{2}}}
$$

and norm $\|V\|=\sqrt{(V, V)}$.

From the results of the work [38] - [40] we obtain 
Proposition 1 Let $N$ - sufficient integer number. If $n>N$ the following statement holds true.

1) The systems of equations (48) and (49)-(50) have a unique solution.

2) The functions $V_{q, n}^{-}(\tau)$ and $V_{q, n}^{+}(\tau)$ are the polynomials of degree $n-1$.

3) The sequence $\left\{V_{q, n}^{-}\right\}_{n=N+1}^{\infty}$ of solutions of IE system (48) converged to the exact solution of the problem (42) in the norm of space $L_{\rho,-1}^{2}$.

4) The sequence of solutions of singular equation system (49)-(50) converged to the exact solution of the problem (43)-(44) in the norm of space $L_{\rho,-1}^{2}$.

It follows from Proposition 1 that, as a result of substituting the functions $V_{q, n}^{+}(\tau)$ into the left-hand side of equations (48) we obtain a polynomial of degree n-1. Also, the result of substituting the polynomial $V_{q, n}^{-}(\tau)$ into the left-hand side of equation (49) is a polynomial of degree $n-2$. On the right side of equations (48) and (49) are polynomials of the same degrees. From the uniqueness of determining a polynomial of degree $n$ from its values at $n+1$ point, there follows a one-to-one correspondence of problems (48) and (49)-(50) to the system of equations:

$$
\begin{gathered}
V_{q, n}^{+}\left(\xi_{1, n, r}\right)-\frac{\phi_{q} \cdot h}{\pi} \cdot \sum_{m=1}^{n} \sqrt{1-\left(t_{2, n, m}\right)^{2}} \cdot l_{2, n, m}\left(\xi_{1, n, r}\right) \cdot \int_{-1}^{1} \ln \left|\tau-t_{2, n, m}\right| \cdot \frac{V_{q, n}^{+}(\tau) d \tau}{\sqrt{1-\tau^{2}}} \\
+\frac{1}{\pi} \sum_{p=1}^{M} \int_{-1}^{1} K_{q, p, n}^{+}\left(\xi_{1, n, r}, \tau\right) \frac{V_{p, n}^{+}(\tau) d \tau}{\sqrt{1-\tau^{2}}}=f_{1, q, n}\left(\xi_{1, n, r}\right), \\
r=1, \cdots, n, q=1, \cdots, M ; \\
\frac{1}{\pi} \int_{-1}^{1} \frac{1}{\tau-\xi_{2, n, s}} \cdot \frac{V_{q, n}^{-}(\tau) d \tau}{\sqrt{1-\tau^{2}}+\frac{1}{\pi} \sum_{p=1}^{M} \int_{-1}^{1} K_{q, p, n}^{-}\left(\xi_{2, n, s}, \tau\right) \frac{V_{p, n}^{-}(\tau) d \tau}{\sqrt{1-\tau^{2}}}-} \\
\int_{-1}^{1} \frac{V_{q, n}^{-}(\tau) d \tau}{\sqrt{1-\tau^{2}}}=0, \quad \int_{-1}^{\xi_{2, n, s}} \frac{V_{q, n}^{-}(\tau) d \tau}{\sqrt{1-\tau^{2}}}=f_{2, q, n}\left(\xi_{2, n, s}\right),
\end{gathered}
$$

To discretize equations (52) - (54), Hermite's formulas and quadrature formulas of interpolation type [13] are used:

$$
\frac{1}{\pi} \int_{-1}^{1} \frac{1}{\tau-t_{2, n, p}} \cdot \frac{V_{p, n}^{-}(\tau) d \tau}{\sqrt{1-\tau^{2}}}=\frac{1}{n} \sum_{k=1}^{n} \frac{V_{p, n}^{-}\left(t_{1, n, k}\right)}{t_{1, n, k}-t_{2, n, p}}, \quad p=1, \cdots, n-1
$$




$$
\begin{aligned}
& \int_{-1}^{1} \ln |\xi-\tau| \cdot \frac{V_{q, n}^{+}(\tau) d \tau}{\sqrt{1-\tau^{2}}}= \\
& \quad=\frac{1}{n} \sum_{k=1}^{n} V_{q, n}^{+}\left(t_{1, n, k}\right) \cdot\left[\ln 2+2 \sum_{m=1}^{n-1} T_{m}(\xi) \frac{T_{m}\left(t_{1, n, k}\right)}{m}\right], \quad|\xi|<1 ; \\
& \int_{-1}^{\xi} \frac{V_{q, n}^{-}(\tau) d \tau}{\sqrt{1-\tau^{2}}}=\frac{1}{n} \sum_{k=1}^{n} V_{q, n}^{-}\left(t_{1, n, k}\right) \cdot \\
& \cdot\left[\arccos \xi-\pi+\sqrt{1-\xi^{2}} \cdot \sum_{m=1}^{n-1} U_{m-1}(\xi) \cdot \frac{T_{m}\left(t_{1, n, k}\right)}{m}\right], \quad|\xi|<1 ;
\end{aligned}
$$

Note that all formulas (55) - (57) are exact for polynomials of degree n-1.

Also, as a result of discretization of the integral equations (52), (53) and (54), we obtain a system of linear algebraic equations with $q \cdot n$ unknowns

$$
\begin{aligned}
& \vartheta_{q, n, m}^{-}=V_{q, n}^{-}\left(t_{1, n, m}\right), \quad q=1, \cdots, M, \quad m=1, \cdots, n . \\
& \vartheta_{q, n, m}^{+}=V_{q, n}^{+}\left(t_{1, n, m}\right), \quad q=1, \cdots, M, \quad m=1, \cdots, n .
\end{aligned}
$$

The existence and uniqueness of the solution of linear systems is a consequence of the existence and uniqueness of the solution of problems (52) - (54) and their one-to-one correspondence with the systems of integral equations (48)-(50).

By solving these linear systems, we obtain approximate solutions to the systems of integral equations (42) and (43)-(44) by the formulas:

$$
\begin{gathered}
V_{q, n}^{-}(\tau)=\sum_{m=1}^{n} \vartheta_{q, n, m}^{-} \cdot l_{1, n, m}(\tau), \\
V_{q, n}^{+}(\tau)=\sum_{m=1}^{n} \vartheta_{q, n, m}^{+} \cdot l_{1, n, m}(\tau), \quad q=1, \cdots, M .
\end{gathered}
$$

\section{Numerical results.}

We studied the interaction of the E-polarized wave and the grating. The case of normal wave incidence was considered. The calculations were carried out by two discrete mathematical models. The first model is described in paragraph 4 of this paper. The second model is based on the discretization of hypersingular integral equations of the second kind. In paper [37] the justification algorithm for finding a numerical solution of these equations is given. 
Table 1. Absolute values of the Fourier coefficients.

\begin{tabular}{|c|c|c|c|c|c|c|c|c|}
\hline \multirow[b]{2}{*}{$\kappa$} & \multicolumn{4}{|c|}{$\begin{array}{l}\text { The results obtained using } \\
\text { singular equations } \\
\end{array}$} & \multicolumn{4}{|c|}{$\begin{array}{l}\text { The results obtained using } \\
\text { hypersingular equations }\end{array}$} \\
\hline & $a_{0}^{-}$ & $a_{1}^{-}$ & $\left|a_{2}^{-}\right|$ & $a_{3}^{-}$ & $a_{0}^{-}$ & $\mid a_{1}^{-}$ & $\mid a_{2}^{-}$ & $a_{3}^{-}$ \\
\hline 0,1 & 0,999 & 0,014 & 030 & 0.0025 & 999 & 0,013 & $0,0<0$ & 0.0023 \\
\hline 0,3 & 0,99 & 0,042 & 087 & 0,0069 & & 0,041 & 0,085 & 0,0066 \\
\hline 0,5 & 0,972 & 0,073 & 0,144 & 0,0096 & 0,973 & 0,071 & 0,142 & 0,0096 \\
\hline 0,7 & 0,946 & 0,111 & 0,202 & 0,0095 & & & 0,2 & 0,0095 \\
\hline 0,9 & 0,901 & 0,176 & 0,264 & 0.0017 & 04 & 0,172 & 62 & 0,0006 \\
\hline 1,1 & 0,795 & 0,261 & 0,305 & 0,057 & & & & 0,056 \\
\hline 1,3 & 0,753 & 0,227 & 0,345 & 0,0 & & & & 073 \\
\hline 1,5 & 0,700 & 0,209 & & & & & & \\
\hline 1,7 & 0,623 & 0,1 & & & & & & 0,1 \\
\hline 1,9 & 0,490 & 0,179 & 0,541 & 0,088 & 44 & 0,18 & & 0,11 \\
\hline 2,1 & 0,322 & 0,1 & & & & & & \\
\hline 2,3 & 0,377 & & & & & & & 088 \\
\hline 2,5 & 0,406 & 0,0 & & 0,0 & & & & 0,09 \\
\hline 2,7 & 0,424 & & & & & & & 0,095 \\
\hline 2,9 & 0,436 & & & & & & & \\
\hline 3,1 & 0,440 & & & & & & & \\
\hline 3,3 & 0,448 & 0,041 & 0,380 & 0,1 & 16 & 0,04 & 0,379 & 0,109 \\
\hline 3,5 & 0,455 & & & & & & & 0,111 \\
\hline 3,7 & 0,462 & & & & & & & \\
\hline 3,9 & 0,47 & & & & & & & \\
\hline 4,1 & 0,465 & 0,076 & 6 & 0,1 & 0,464 & 6 & 0,325 & 0,157 \\
\hline 4,3 & 0,455 & & & 0, & & & 0,316 & 0,161 \\
\hline 4,5 & & & & & & & & \\
\hline 4,7 & 0,444 & & & & & & 0,308 & 0,164 \\
\hline 4,9 & 0,440 & 0,093 & 0,3 & 0,1 & 0,439 & 0,092 & 0,306 & 0,167 \\
\hline 5 , & 0,458 & 0,0 & & & & & & 0.144 \\
\hline 5,3 & 0,464 & 0,091 & 0,309 & & 0,463 & & 0,308 & 0,127 \\
\hline 5,5 & & & & 0,117 & 0,464 & 0,089 & 0,307 & 0,117 \\
\hline 5,7 & 0,465 & & & 0,11 & & & 0,307 & 0,11 \\
\hline 5,9 & 0,460 & 0,084 & & & 0,458 & 0,083 & 0,307 & 0,102 \\
\hline 6,1 & 0,458 & 0,074 & 0,313 & 0,089 & 0,456 & 0,074 & 0,311 & 0,088 \\
\hline
\end{tabular}

In calculations we take $h^{\prime}$ equals:

$$
h^{\prime}=-\frac{1-i}{2 K} \cdot \sqrt{k}
$$

where $K=0.0001$. 


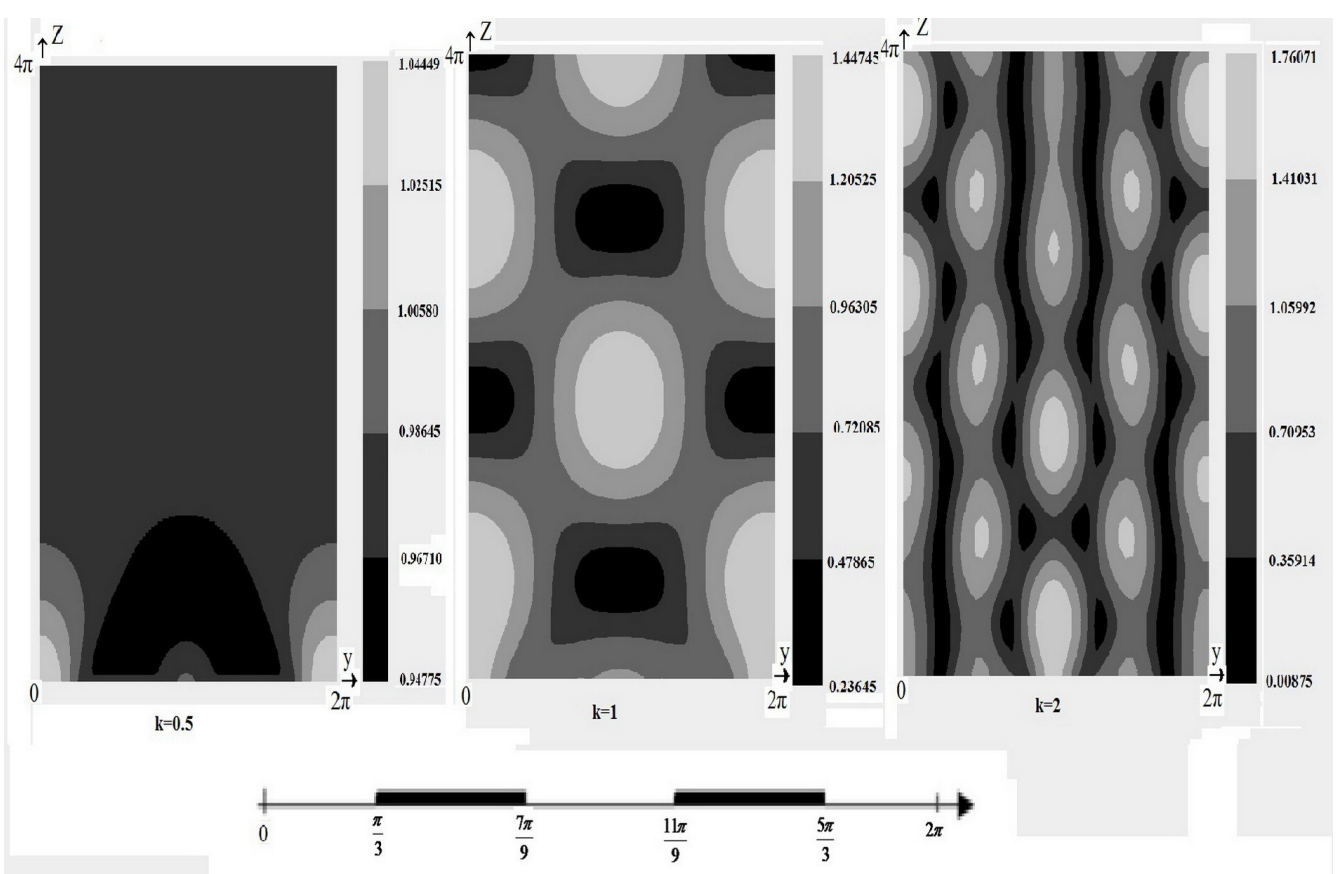

Fig.2 Map of the absolute value of the scattered field in the domain above the two-elements periodic grating. $\alpha_{1}=\frac{\pi}{3}, \quad \beta_{1}=\frac{7 \pi}{9}, \quad \alpha_{2}=\frac{11 \pi}{9}, \quad \beta_{2}=\frac{5 \pi}{3}$.

On figure 2 there are the maps of the absolute value of the scattered field $\left|E^{+}\right|$ in the domain above a two-element periodic structure. The table 1 shows some parameter values in this case obtained using singular and hypersingular equations. The number of interpolation nodes in this case is twenty on tape.

We considered next structure. In the middle of the tape, lying in half the period, a slot $2 \pi$ wide was made. The graths on figure 3 show the change in the field characteristics depending on the slot width. In the figures you can see the absolute values of the Fourier coefficients and values:

$$
\left\|a^{-}\right\|_{N}=\sqrt{\sum_{n=-N}^{N}\left|a_{n}^{-}\right|^{2}} .
$$

We also studied the similarities and differences in the fields created by periodic lattices and lattices consisting of a large finite number of repeating elements. For example, at the top of figure 4 you see a colored map of the field in the domain above periodic structure. In this case one tape lies on half the period. Below there is a map of the scattered field above the central part of the non-periodic structure. This structure consists of fifteen equal tapes. The distance between the tapes and their width are the same and equal to $\pi$. 

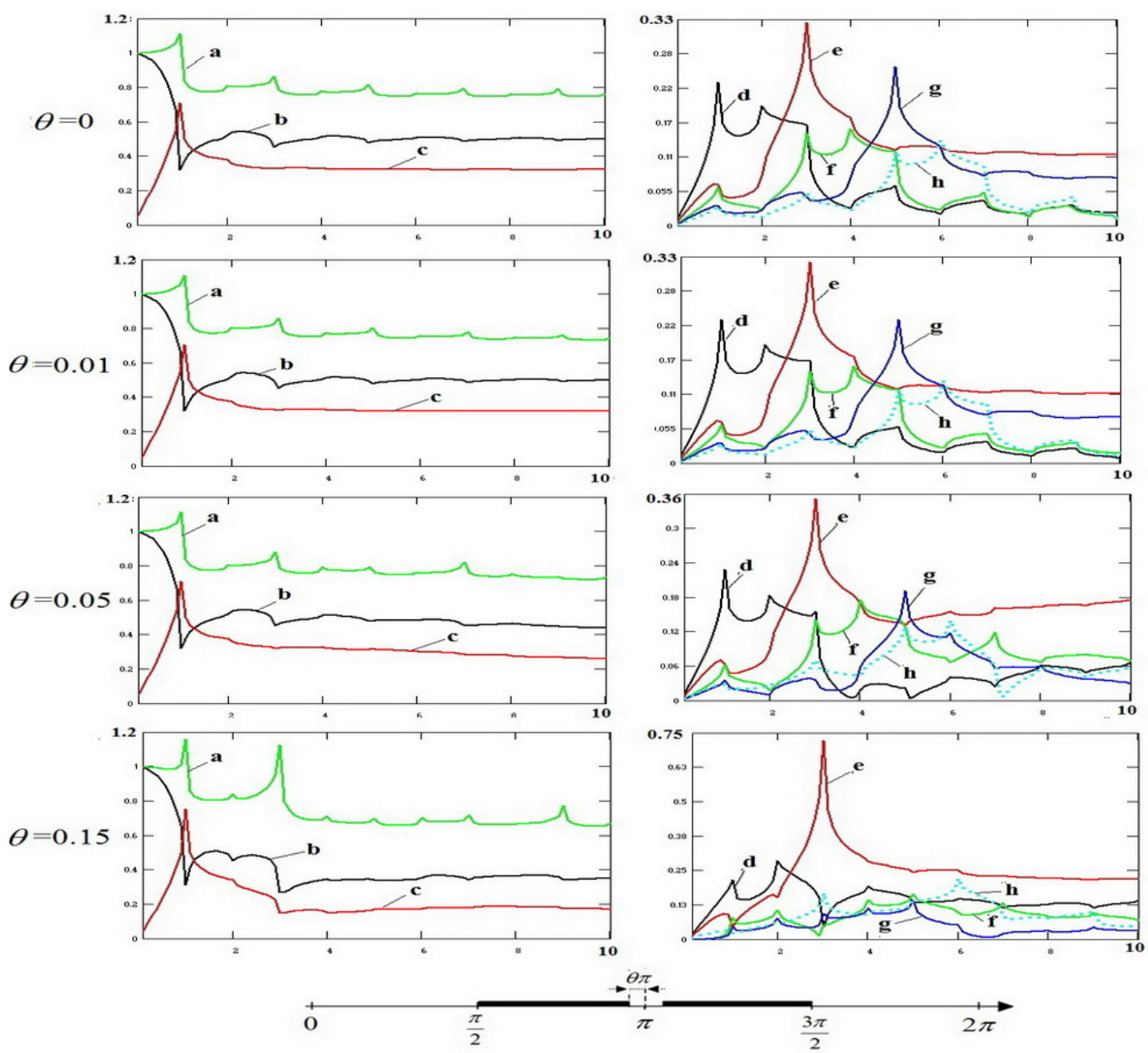

Fig.3 Tape with slot $2 \pi \theta$ wide on the period.

a) $\left\|a^{+}\right\|_{10}$, b) $\left|a_{0}^{+}\right|$, c) $\left|a_{1}^{+}\right|$, d) $\left|a_{2}^{+}\right|$, f) $\left|a_{3}^{+}\right|$, g) $\left|a_{4}^{+}\right|$, h) $\left|a_{5}^{+}\right|$. 


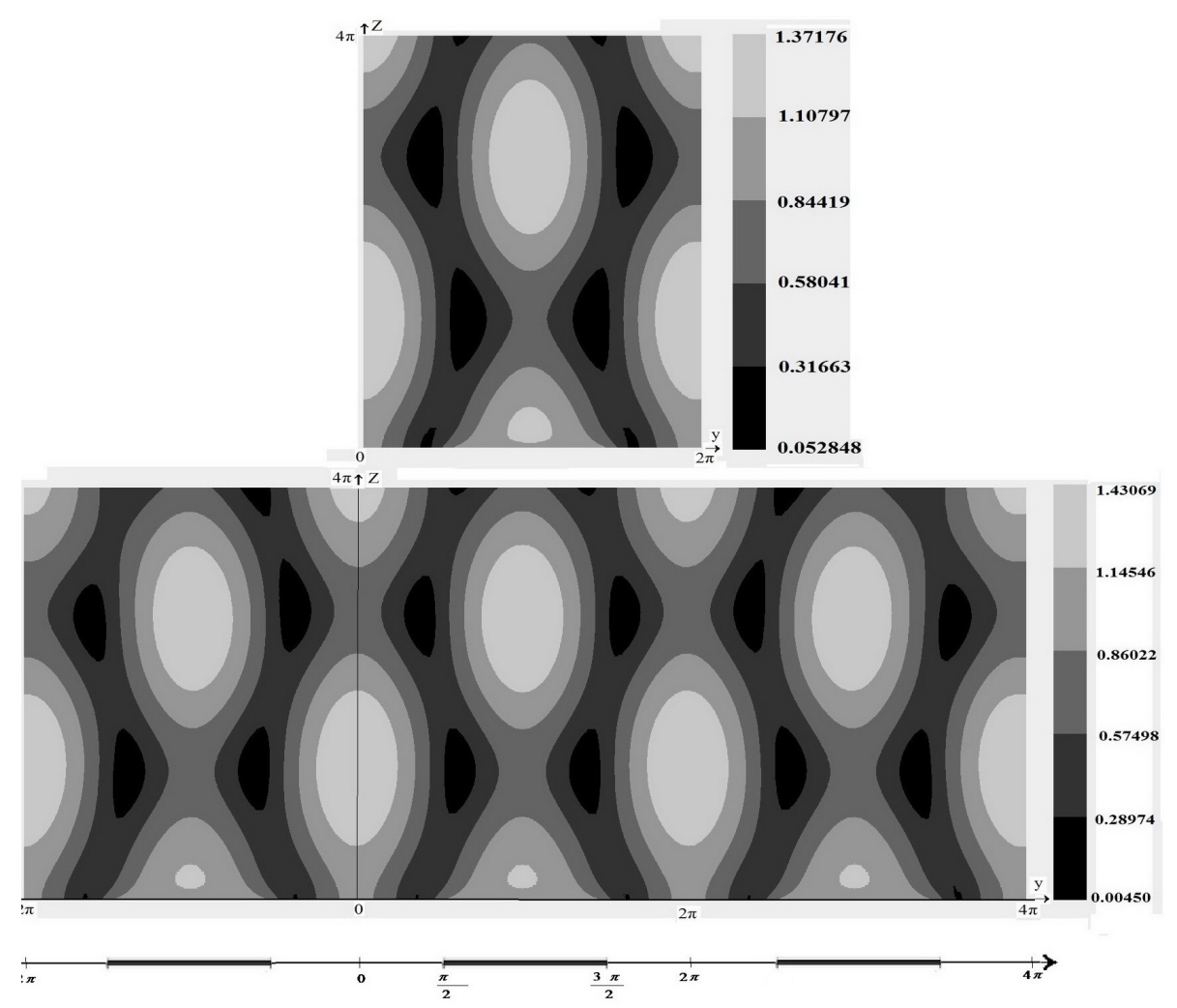

Fig.4 Map of the absolute value of the scattered field in periodic and non-periodic case, $\kappa=1.1$

On fig. 5-6 we consider a five-element periodic structure. On the period, four tapes have the same length, and the fifth tape has a defect on the right. You can see the field characteristics for some values of theta. Graphs on figure 4 show the field characteristics for some values of theta. On fig. 5 there are colored maps of the scattered field in the domain above this structure.

\section{Conclusions and directions for further research.}

The results of the performed numerical experiments showed are in a good agreement of the obtained numerical results with the results obtained using hypersingular integral equations. The performed experiment is a basis for the numerical investigation of more complex impedance structures. These studies are related to the work carried out at the Department of Applied Mathematics of the School of Mathematics and Informatics of V. N. Karazin Kharkiv National University for topic (017U004831) "Modeling the dynamics of complex systems in order to identify problem situations". Publication contains some results based on a research provided by grant support of the State Fund for Fundamental Research (project F-83). 

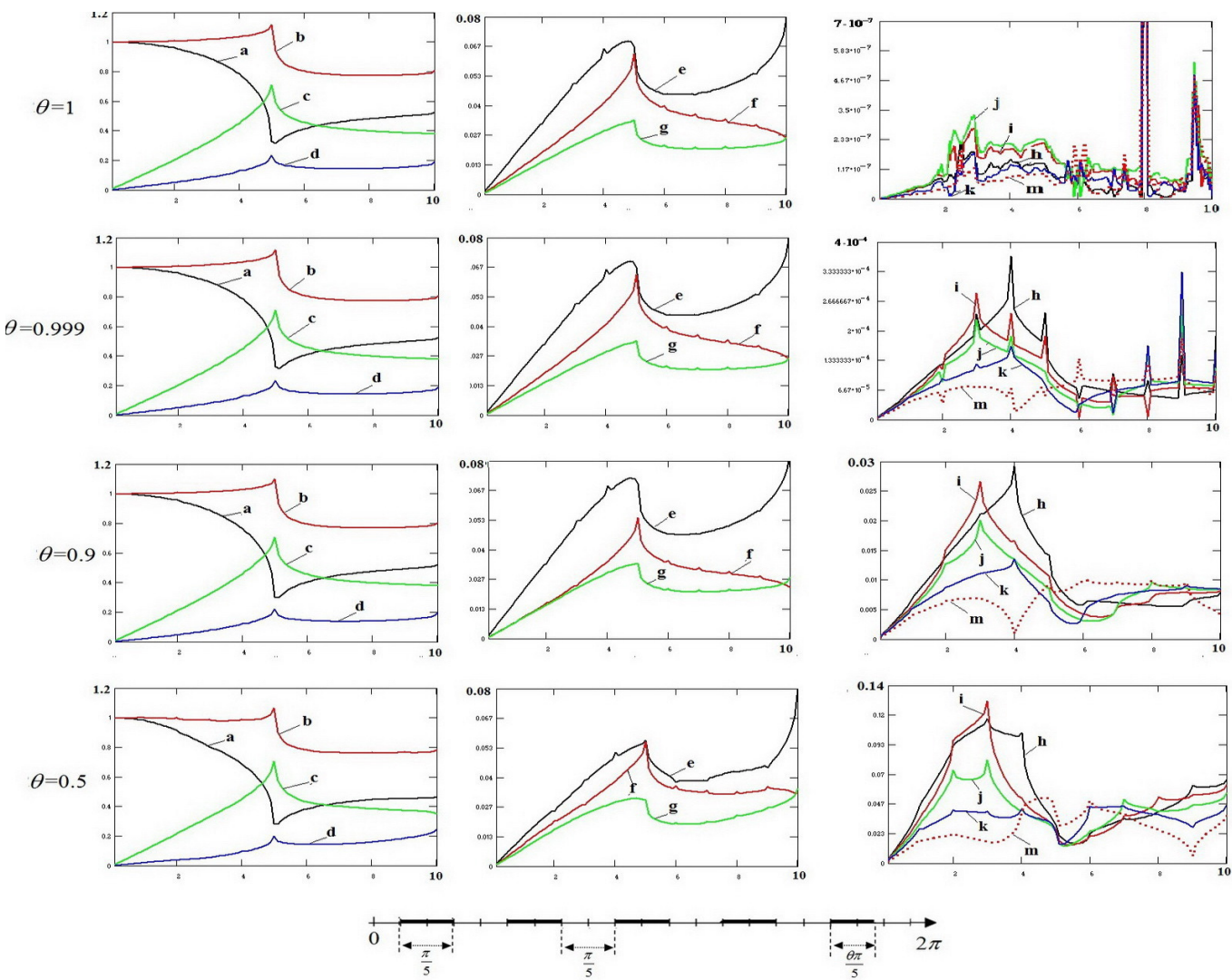

Fig. 5 Amplitude transmission characteristics of five elements gratings a) $\left|a_{0}^{-}\right|$, b) $\left\|a^{-}\right\|_{25}$, c) $\left|a_{5}^{-}\right|$, d) $\left|a_{10}^{-}\right|$, e) $\left|a_{15}^{-}\right|$, f) $\left|a_{20}^{-}\right|$, g) $\left|a_{25}^{-}\right|$, h) $\left|a_{1}^{-}\right|$, i) $\left|a_{2}^{-}\right|$, j) $\left.\left.\left|a_{3}^{-}\right|, \mathrm{k}\right)\left|a_{4}^{-}\right|, \mathrm{m}\right)\left|a_{6}^{-}\right|$.
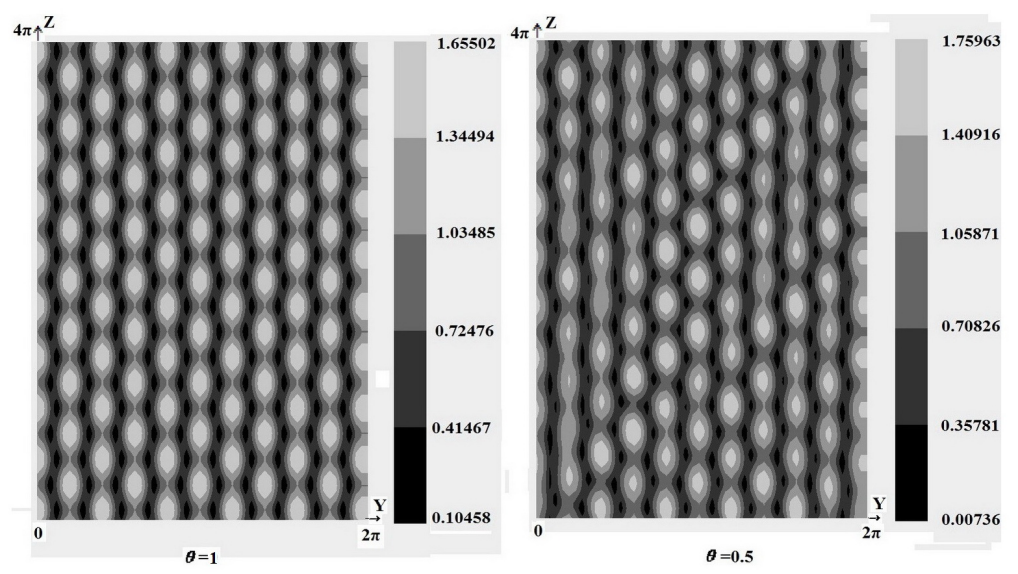

Fig. 6 Map of the absolute value of the scattered field in the domain above the five-elements periodic grating. 


\section{ORCID ID}

V.D.Dushkin (iD https://orcid.org/0000-0002-5143-7945

S. V.Zhuchenko (iD https://orcid.org/0000-0002-1946-7044

O. V. Kostenko (iD https://orcid.org/0000-0002-9471-8894

\section{REFERENCES}

1. A. S. Il'insky, A. Ja. Slepjan, G. Ja. Slepjan, Propagation, diffraction and dissipation of electromagnetic waves. 1993. London (UK): The IEE and Peter Peregrinous Ltd., Electromagnetic Waves, Ser. 36. 275 p.

2. O. O. Bulatsyk, B. Z. Katsenelenbaum, Yu. P. Topolyuk, N. N. Voitovich. Phase Optimization Problems: Applications in Wave Field Theory. 2010. Hoboken, NJ: Wiley-VCH, Weinheim, 321 p.

3. T. L. Zinenko, A. I. Nosich. Wave Scattering and Absorption by Flat Gratings of Impedance Strips, IEEE Transactions on Antennas and Propagation, 2006. - V.54. - P. 2088-2095.

4. V. F. Kravchenko. The electrodynamics of superconducting structures. The theory, algorithms and computational methods, 2006. Fizmatlit, Moscow, 280 p.

5. Yu. Penkin, V. Katrych, M. Nesterenko, S. Berdnik. Coupling of Two Rectangular Waveguides Through a Slot With an Impedance Membrane, VII th International Conference on Mathematical Methods in Electromagnetic Theory. Kyiv, Ukraine, - 2018. - P. 140-143.

6. G. I. Koshovy. Mathematical models of acoustic wave scattering by impedance strip, Proceedings of the XXII-nd International Seminar/Workshop on Direct and Inverse Problems of Electromagnetic and Acoustic Wave Theory (DIPED-2017), - 2017. - P. 71-74.

7. Yu. V. Gandel', V.F. Kravchenko, V.I. Pustovoit. Scattering of electromagnetic waves by a thin superconducting band, Doklady Math, - 1996. - 54. - no. 3. - P. 959-961.

8. Yu. V. Gandel, V. F. Kravchenko, N. N. Morozova. Electromagnetic wave diffraction on a lattice of thin superconducting band, Electromagnetic Waves and Electronic Systems, - 1997. - 2, no. 1. - P. 4-15.

9. Yu.V. Gandel. Parametric Representations of Integral and Psevdodifferential Operators in diffraction Problems, Proceedings of the $\mathrm{X}$ International Conference on Mathematical Methods in Electromagnetic Theory, Dnipropetrovsk, Ukraine, 2004. - P. 57-62. 
10. Yu. V. Gandel. Boundary-Value Problems for the Helmholtz Equation and their Discrete Mathematical Models, Journal of Mathematical Sciences, Springer Science+Business Media, Inc., - 2010. - Vol. 171, no. 1. - P. 74-88.

11. Y.V. Gandel, V.D. Dushkin. The method of parametric representations of integral and pseudo-differential operators in diffraction problems on electrodynamic structures, Proceedings of the International Conference Days on Diffraction DD, St. Petersburg, - 2012. - P. 76-81.

12. I. K. Lifanov. Singular integral equations and discrete vortices. 1996. - Utrecht (the Netherlands): VSP VB, 475 p.

13. Yu.V. Gandel, V.D. Dushkin. Mathematical models of two-dimensional diffraction problems: Singular integral equations and numerical methods of discrete singularities method. 2012. Academy of IT of the MIA of Ukraine, Kharkiv, - 544 p. (in Russian).

14. V.D. Dushkin. Mathematical models of two-dimensional diffraction problems, Proceedings of the VI th International Conference on Mathematical Methods in Electromagnetic Theory (MMET'96), Lviv, 1996. V. 1, - P. 483-486.

15. V.A. Shcherbina, G.I. Zaginaylov, S.V. Zhuchenko. Numerical theory of excitation of axisymmetric open-ended finite length slow wave structure on the basis of the boundary singular integral equation method, VII th International Conference on Mathematical Methods in Electromagnetic Theory (MMET'98), Kharkov, Ukraine, - 1998. - V. 1, - P. 263-265.

16. G.I. Zaginaylov, V.D. Dushkin, V. Korostyshevski, P.V. Turbin. Modeling the beam excitation of planar waveguide with rectangular irregularities, Proceedings of the VII th International Conference on Mathematical Methods in Electromagnetic Theory (MMET'98); Kharkov, Ukraine, - 1998 - V. 1, P. 409-410.

17. Yu.V. Gandel, G.L. Sidel'nikov. The method of integral equations in the third boundary value problem of diffraction on a bounded grating over a flat screen, - Differential Equations, - 1999.- 35, no. 9. - P. 1169-1175.

18. V.D. Dushkin. Solution of a two-dimensional diffraction problem with boundary conditions of the third kind on the lateral surface of waveguide channels, Reports of the NAS of Ukraine, - 1999.- no. 9 - P. 11-15. (in Russian).

19. Y.V. Gandel, V.D. Dushkin, G.I. Zaginaylov. New numerical-analytical approach in the theory of excitation of super dimensional electro dynamical structures Telecommunications and Radio Engineering (English translation of Elektrosvyaz and Radiotekhnika), - 2000.- V. 54, 7. - P. 36-48. 
20. V.D. Dushkin. Application of the singular integral transform method to the solution of the two-dimensional problem of diffraction of electromagnetic waves from a superconducting layer with rectangular waveguide channels, Telecommunications and Radio Engineering (English translation of Elektrosvyaz and Radiotekhnika), - 2001. - V. 56, Issue 2. P. 78-85.

21. A. A. Nosich, Y. V. Gandel. Numerical analysis of quasioptical multi-reflector antennas in 2-D with the method of discrete singularities, IEEE Transactions on Antennas and Propagation, - 2007. - V. 57, no. 2. - P. 399-406.

22. Yu.V. Gandel, V.D. Dushkin. Mathematical models based on SIE 2D diffraction problems on reflective multilayer periodic structures, Part I. The case of E-polarization, Scientific statements. Series: Mathematics. Physics. Belgorod State National Research University, - 2011.- V. 5 (100), 2. - P. 5-16. (in Russian).

23. V.S. Bulygin, A.I. Nosich, Y.V. Gandel. Nystrom-type method in threedimensional electromagnetic diffraction by a finite PEC rotationally symmetric surface, IEEE Transactions on Antennas and Propagation, - 2012. - 60 (10). - P. 4710-4718.

24. S.V. Zhuchenko. Numerical model diffraction of the plane electromagnetic wave onto axiallysymmetric parabolic reflector, Bulletin of V. Karazin Kharkiv National University, Series "Mathematical Modelling. Information Technology. Automated Control Systems - 2013.- Issue 22, no. 1063 - P. 6371. (in Russian).

25. S.V. Zhuchenko. Discrete mathematical model of electromagnenic wave 3D diffraction on axially symmetric reflector, Bulletin of V. Karazin Kharkiv National University, Series "Mathematical Modelling. Information Technology. Automated Control Systems - 2013. - Issue 23, no. 1089 - P. 50-68. (in Russian).

26. K. V. Nesvit. Scattering and Diffraction of TM Modes on a Grating Consisting of a Finite Number of Pre-Fractal Thin Impedance Strips, Proceedings of the 43rd European Microwave Conference (EuMC). - Nuremberg, Germany, - 6-11 October 2013. - P. 1143-1146.

27. V.D. Dushkin. Mathematical Models of Plane Wave Scattering on Multilayer Impedance Structures, Visnyk of the Lviv University. Series "Applied Mathematics and Computer Science- 2013. - 20. - P. 69-76.

28. Y.V. Gandel, V.D. Dushkin. The boundary integral equations of the third boundary-value problem for the Helmholtz equation in the $R_{+}^{2}$ with planeparallel slits, Reports of the NAS of Ukraine, - 2014. - no. 8 - P. 14-19. 
29. K. V. Nesvit. Scattering and Propagation of the TE/TM Waves on Pre-Fractal Impedance Grating in Numerical Results, Proceedings of 8th European Conference on Antennas and Propagation (EuCAP), - Hague, Netherlands, 6-11 April 2014. - P. 3349- 3353.

30. O. V. Kostenko. Mathematical model of wave scattering by an impedance grating, Cybernetics and systems analysis, - 2015. - V. 51, no. 3. - P. 344-360.

31. S.V. Dukhopelnikov. Inhomogeneities in the antenna cavity and the diffractive properties of antennas of a special form Numerical analysis, Part 1, Bulletin of V. Karazin Kharkiv National University, Series "Mathematical Modelling. Information Technology. Automated Control Systems - 2016. - 32. - P. 25-34.

32. O. V. Kostenko. A numerical method for solving a system of hypersingular integral equations of the second kind, Cybernetics and systems analysis, 2016. -V. 52, no. 3. P. 394-407.

33. Yu. V. Gandel, V. D. Dushkin. Mathematical Model of Scattering of Polarized Waves on Impedance Strips Located on a Screened Dielectric Layer, Journal of Mathematical Sciences, Springer US, - 2016. - P. 156-166.

34. S. V. Dukhopelnykov. Control of backscattering of H-polarized plane wave by a circular dielectric rod with partial graphene cover, Proc. Int. Seminar/Workshop on Direct and Inverse Problems of Electromagnetic and Acoustic Wave Theory (DIPED-2018), Tbilisi, - 2018. - P. 51-54.

35. S. V. Dukhopelnykov, R Sauleau, M Garcia-Vigueras, A.I. Nosich. "Combined plasmon-resonance and photonic-jet effect in the $\mathrm{THz}$ wave scattering by dielectric rod decorated with graphene strip, J. Appl. Phys. - 2019. - V. 126, no. 2 - 023104.

36. V.D. Dushkin, S.V. Zhuchenko, O.V. Kostenko. Numerical analysis of wave scattering by periodic systems of impedance tapes, Proc. Int. Seminar/Workshop on Direct and Inverse Problems of Electromagnetic and Acoustic Wave Theory (DIPED-2019), Lviv, - 2019.- p. 112-116.

37. O. V. Kostenko. Numerical method for the solution of a hypersingular integral equation of a second kind, Ukrainian mathematical journal, - 2014. - V. 65, no. 9. - P. 1373-1383.

38. V.D. Dushkin. The Justification of Numerical Solution of Boundary Integral Equations of Wave Scattering Problems on Impedance Lattice, Visnyk of V.N.Karazin Kharkiv National University, Ser. "Mathematics, Applied Mathematics and Mechanics - 2014. - 69. - P. 20-28.

39. Yu. V. Gandel ,V.D. Dushkin. The Approximate Method for Solving the Boundary Integral Equations of the Problem of Wave Scattering by 
Superconducting Lattice, American Journal of Applied Mathematics and Statistics, Science and Education Publishing, - 2014. - 2.6. - P. 369-375

40. V. D. Dushkin. Approximate solving of the third boundary value problems for Helmholtz equations in the plane with parallel cuts, Zh. Mat. Fiz. Anal. Geom, - 2017. - 13:3. - P. 254-267.

Душкін В.Д, Жученко С.В., Костенко О.В. Дискретна математична модель процесу розсіювання хвиль періодичною імпедансною граткою. У статті розглядається спосіб чисельного моделювання процесу розсіювання хвиль періодичною імпедансною граткою. У разі гармонійної залежності поля від часу і однорідності структури уздовж деякої осі тривимірна задача зводиться до розгляду двох двовимірних задач для компонент Е-поляризованої і Н-поляризованої хвилі. Шукана єдина ненульова компонента електричного поля, створеного падаючою Еполяризованої хвилею, $є$ рішенням крайової задачі для рівняння Гельмгольца з граничними умовами Робена. 3 фізичної постановки задачі випливає, що іiї рішення повинні задовольняти умові квазіперіодичності Флоке, умовою скінченості енергії в будь-який обмеженій області площині. Також різниця повного і падаючого поля повинна задовольняти умові випромінювання Зоммерфельда. Слідуючи ідеям робіт Ю.В. Ганделя, за допомогою методу параметричних уявлень інтегральних операторів крайова задача зводиться до двох систем інтегральних рівнянь. Перша система складається з сингулярних рівнянь першого роду з додатковими інтегральними умовами. Друга система складається з граничних інтегральних рівнянь Фредгольма другого роду з логарифмічною особливістю в підінтегральній функції. Був проведений чисельний експеримент для випадків різного розташування стрічок. Обчислення проводилися для моделі на основі сингулярних рівнянь і моделі на основі гіперсінгулярних рівнянь. Вони показали близькість отриманих результатів у діапазоні досліджуваних параметрів.

Ключові слова: математична модель; імпедансні структури; чисельний експеримент.

V.D. Dushkin, S.V. Zhuchenko, O.V. Kostenko. Discrete mathematical model of the scattering process of E-polarized wave on a periodic impedance grating. The method of numerical modeling of wave scattering by periodic impedance grating is considered. In the case of a harmonic dependence of the field on time and the uniformity of the structure along a certain axis, the three-dimensional problem reduces to considering of two $2 \mathrm{D}$ problems for the components of the E-polarized and $\mathrm{H}$-polarized waves. The signle nonzero component of the electric field created by the incident E-polarized wave is the solution of the boundary value problem for the Helmholtz equation with Robin boundary conditions. It follows from the physical formulation of the problem that its solutions satisfy the Floquet quasiperiodicity condition, the condition of finiteness of energy in any bounded region of the plane. Also, the difference between the total and incident fields satisfies the Sommerfeld radiation condition. Following the ideas of the works of Yu.V. Gandel, using the method of parametric representations of integral operators, the boundary-value problem reduces to two systems of integral equations. The first one is the system of singular equations of the first kind with additional integral conditions. The second system consists of the Fredholm boundary integral equations of the second kind with a logarithmic singularity in the integrand. A discrete model for various values of the discretization parameter is equivalent to systems of singular integral equations. By solving these equations, approximate values of the main field characteristics are determined. The method of parametric representations of integral operators makes it possible to obtain 
systems of integral equations of other types. In particular, the initial boundary-value problem reduces to a system consisting of hypersingular integral equations of the second kind and the Fredholm integral equation of the second kind. A numerical experiment was conducted for cases of different location of tapes. Calculations were performed for the proposed model and the model based on hypersingular equations. They showed the closeness of the obtained results in a wide range of parameters studied.

Keywords: mathematical model; impedance structures; numerical experiment.

Article history: Received: 16 April 2019; Final form: 20 November 2019;

Accepted: 22 November 2019. 